\title{
CARACTERÍSTICAS BIOMÉTRICAS EM CULTIVARES DE FEIJÃO-CAUPI
}

\section{BIOMETRIC CHARACTERISTICS IN CULTIVARS OF COWPEA}

\section{João Fernandes da Silva Junior ${ }^{1}$, Marcela Caetano Lopes ${ }^{2}$, Saulo Strazeio Cardoso ${ }^{3 *}$}

\author{
${ }^{1}$ Departamento de Topografia, IFPA \\ ${ }^{2}$ Departamento de Ciências Biológicas da Faculdade de Ciências, UNESP, Av. Luiz \\ Edmundo Carrijo Coube no 14-01. Bairro Vargem Limpa, Bauru, SP. CEP 17033-360 \\ ${ }^{3 *}$ Departamento de Solos e Adubos, UNESP, Via de Acesso Prof. Paulo Donato \\ Castellane s/n 14884-900, SPUNESP, Jaboticabal \\ *Autor para correspondência E-mail: strazeio@yahoo.com.br
}

\begin{abstract}
RESUMO
O feijão-caupi é uma das principais culturas leguminosas do nordeste, tendo grande importância socioeconômica para o sistema de produção da agricultura familiar. É consumido sob as formas de grãos secos e verdes, além de seus caules e ramos serem usualmente utilizados na alimentação animal. Neste sentido, o presente trabalho objetivou verificar qual das cultivares de feijão-caupi se desenvolve melhor na região de Belém e estimar as correlações fenotípicas entre as variáveis biométricas avaliadas. O experimento foi conduzido na Universidade Federal Rural da Amazônia / UFRA - Belém-PA. Foram utilizadas quatro cultivares de feijão-caupi: BR3-Tracuateua, BRS Urubuquara, BRS Milênio e Pretinho, em um delineamento com blocos ao acaso contendo quatro repetições para avaliar as seguintes características biométricas: número de ramos planta $^{-1}$ (NR), comprimento das hastes $(\mathrm{CH})$, número de inflorescências planta ${ }^{-1}(\mathrm{NI})$ e o número de folhas planta ${ }^{-1}$ (NF). Por meio da análise de variância foi realizada uma correlação entre as características biométricas para cada cultivar. Assim, nas condições em que o experimento foi realizado, verificouse que a cultivar Pretinho apresentou-se menos produtivo para o número de ramos em relação às cultivares: BR3-Tracuateua e BRS Milênio. Além disso, apesar das cultivares apresentarem desempenho semelhante, são recomendados novos experimentos com maior número de acessos e repetições.
\end{abstract}

Palavras-chave: Correlação. Vigna unguiculata (L.) Walp. Leguminosa.

\footnotetext{
ABSTRACT

Cowpea is a major legume crops northeast, having great socio-economic importance for the production system of family farming. It is consumed in the forms of dry and green beans, plus their stems and branches are usually used in animal feed. In this sense, the present study aimed to determine which cultivars of cowpea grows best in the Bethlehem area and estimate the phenotypic correlations between the assessed biometric variables. The experiment was conducted at the Federal Rural University of Amazonia / UFRA - Belem-PA. Four cowpea cultivars were used: BR3-
} 
Tracuateua, Urubuquara BRS, BRS Millennium Pretinho and, in a complete randomized block design to evaluate the following biometrics character: number of branches plant-1 (NR), length of stems $(\mathrm{CH})$, number of inflorescence plant-1 (NI) and the number of leaves plant-1 (NF). Through the analysis of variance is a correlation between the biometric characteristics of each cultivar was performed. Thus, under conditions in which the experiment was conducted, it was found that the cultivar Pretinho were less productive for the number of branches in relation to cultivars: BR3Tracuateua and BRS Millennium. Furthermore, despite the cultivars exhibited similar performance, new experiments with more hits and repetitions are recommended.

Keywords: Correlation. Vigna unguiculata (L.) Walp. Legumes.

\section{INTRODUÇÃO}

O feijão-caupi [Vigna unguiculata (L.) Walp], conhecido como feijão de corda, feijão macassar e feijão miúdo é uma das principais leguminosas cultivadas na região Nordeste e Norte do Brasil (OLIVEIRA et al., 2013). Este pode ser consumido sob as formas de grãos secos e verdes, além de seus caules e ramos serem usualmente utilizados na alimentação animal. Além disto, pode ser utilizado como forragem verde, feno, silagem, farinha para alimentação animal e, ainda, como adubo verde na recuperação de solos de baixa fertilidade natural, ou esgotados pelo uso intensivo, muito comum nessa região (ANDRADE JÚNIOR, 2000; SILVA, 2006).

Embora considerada uma cultura tropical, compatível com as condições ecológicas locais, esse tipo de feijão é cultivado em pequenas áreas, tanto no sistema solteiro como no consorciado com outras culturas, principalmente com o milho ou mandioca (ALVES et al., 2009; ALBUQUERQUE et al., 2012).

As cultivares de feijão-caupi apresentam características genéticas, fisiológicas e morfológicas intrínsecas e, portanto, respondem de forma diferenciada as condições edafoclimáticas locais. Nesse sentido, alguns trabalhos foram desenvolvidos com linhagens e variedades visando indicar as mais adaptadas às condições de cada região (SANTOS et al., 2009). A escolha correta da cultivar para um determinado ambiente e sistema de produção são de grande importância para a obtenção de bons rendimentos. Isso por si, contudo, só não é suficiente para o sucesso da exploração. É necessário, também que a cultivar tenha características de grão e de vagem, que atendam às exigências de comerciantes e consumidores (FREIRE FILHO et al., 2000).

Esses estudos têm subsidiado o melhoramento e o lançamento de cultivares de feijão-caupi em vários estados do Nordeste (FREIRE FILHO et al., 2001; 2002). Atualmente, têm-se buscado modelos alternativos de análises que expliquem melhor o comportamento de genótipos frente às variações ambientais. Neste sentido, o presente estudo teve por objetivo avaliar quais cultivares de feijão-caupi se desenvolvem melhor na região de Belém e estimar as correlações fenotípicas entre as variáveis biométricas avaliadas.

\section{MATERIAL E MÉTODOS}

O experimento foi conduzido em condições de campo na área experimental da Universidade Federal Rural da Amazônia / UFRA - Belém - PA, situada próximo às coordenadas centrais $01^{\circ} 28^{\prime}$ 03'S e 48 29' 18'E. Bastos (1986) caracterizou o clima como tropical chuvoso sem variação térmica estacional e apresentando total pluviométrico anual elevado, com mês menos chuvoso inferior a $60 \mathrm{~mm}$ e com moderado período de estiagem.

As formas de relevo preponderante na área experimental são consideradas planas, com declives entre 0 a 3\%, ligeiramente onduladas. Os solos predominantes na área são do grupo dos 
Latossolos Amarelos textura média, fortemente lixiviados, com baixa fertilidade natural e o teor de argila aumenta com a profundidade.

No preparo da área foi realizada uma roçagem mecânica e os restos culturais foram destinados à cobertura morta para proteção do solo. Foram coletadas várias sub-amostras de solo antes do semeio das sementes de feijão, constituindo-se amostra composta, sendo levada ao laboratório de solos da UFRA, para análises químicas e físico-químicas. Com base nos resultados encontrados quanto à analise química do solo fez-se as recomendações necessárias de acordo com Cravo et al. (2007).

As cultivares de feijão-caupi utilizadas foram BR3-Tracuateua, BRS Urubuquara, BRS Milênio e Pretinho. O delineamento experimental utilizado foi em blocos ao acaso com quatro repetições, para controlar a diferença de fertilidade existente no solo, cujas parcelas experimentais apresentavam uma área de $24 \mathrm{~m}^{2}$.

A semeadura das cultivares de feijão-caupi foi realizada no dia 20/06/2008, consistindo na distribuição manual de 14 a 15 sementes por metro linear, utilizando-se o espaçamento de $0,50 \mathrm{~m}$ entre linhas. Aos 35 dias após a emergência, foram coletadas 6 plantas. $\mathrm{m}^{-1}$ de forma aleatória dentro das parcelas. A partir deste material foi realizada a contagem do número de ramos planta ${ }^{-1}(\mathrm{NR})$, comprimento das hastes $(\mathrm{CH})$, números de inflorescências planta ${ }^{-1}(\mathrm{NI})$ e de folhas planta ${ }^{-1}(\mathrm{NF})$.

Com estas características biométricas, testaram-se as hipóteses de normalidade e de homogeneidade de variância e em seguida foram avaliados os diferentes efeitos delas por meio das comparações entre as médias obtidas em cada tratamento, foi utilizado o Teste de Tukey a $5 \%$ de probabilidade. Para verificar o grau de associação dos parâmetros biométricos das cultivares, calculou-se o coeficiente de correlação linear simples de Pearson ${ }^{\circledR}$ para avaliar a influência dessas características em inferir a sua produção (PIMENTEL-GOMES, 2000).

\section{RESULTADOS E DISCUSSÃO}

As análises químicas das amostras da camada de $0-20 \mathrm{~cm}$ de solo na área de estudo foram: $\mathrm{pH}\left(\mathrm{H}_{2} \mathrm{O}\right)=5,8 ; \mathrm{P}=362,84 \mathrm{mg} \mathrm{dm}{ }^{-3} ; \mathrm{K}=0,08 \mathrm{mg} . \mathrm{Dm}^{-3} ; \mathrm{Ca}^{+2}=3,77 \mathrm{cmolc} . \mathrm{dm}^{-3}$. Foram observadas diferenças entre as cultivares para o número de ramos por planta, pela análise de variância cujo valor de $\mathrm{F}$ acusou diferenças estatísticas significativas ao nível de $1 \%$ de probabilidade, não tendo sido verificadas diferenças estatísticas significativas para comprimento da haste, número de inflorescência e número de folhas (Tabela 1).

Tabela 1 - Resumo da análise de variância para os caracteres: número de ramos planta ${ }^{-1}(\mathrm{NR})$, comprimento de haste $(\mathrm{CH})$, número de inflorescências planta $^{-1}(\mathrm{NI})$ e número de folhas planta ${ }^{-1}(\mathrm{NF})$ de quatro cultivares de feijão-caupi.

\begin{tabular}{|c|c|c|c|c|c|}
\hline \multirow[t]{2}{*}{ Fonte de Variação } & \multirow[t]{2}{*}{ GL } & \multicolumn{4}{|c|}{ Quadrados Médios } \\
\hline & & NR & $\mathrm{CH}$ & NI & $\mathrm{NF}$ \\
\hline Blocos & 3 & $1,02^{\mathrm{ns}}$ & $195,72^{\mathrm{ns}}$ & $20,72^{\mathrm{ns}}$ & $0,66^{\mathrm{ns}}$ \\
\hline Cultivares & 3 & $20,13 * *$ & $590,17^{\mathrm{ns}}$ & $2,13^{\mathrm{ns}}$ & $2,14^{\mathrm{ns}}$ \\
\hline Erro & 9 & 4,22 & 235,74 & 3,21 & 1,15 \\
\hline F Calculado & & 14,30 & 2,50 & 0,66 & 1,86 \\
\hline
\end{tabular}

**Significativo em nível de $1 \%$ de probabilidade; ns = não significativo 
As cultivares não apresentaram diferenças significativas entre as características biométricas: comprimento de haste, número de inflorescências planta $^{-1}$ e número de folhas planta ${ }^{-1}$. Para o número de ramos planta $^{-1}$, porém, a cultivar Pretinho apresentou diferença significativa em relação às demais, a qual teve potencial de produção de matéria fresca, baseada no número de ramos, menor. A cultivar Milênio, entretanto, se sobressaiu, mas, não diferenciando do BR3-Tracuateua e BRS Urubuquara, sendo que esta última não apresentou diferença significativa do BRS-Tracuateua e do Pretinho (Tabela 2). Resultados semelhantes foram observados por Freire Filho et al. (2009) ao avaliarem características fenológicas e agronômicas das cultivares BRS Milênio e BRS Urubuquara de feijão-caupi para a região Bragantina do Estado do Pará.

Tabela 2 - Médias do número de ramos planta $^{-1}(\mathrm{NR})$, comprimento de haste $(\mathrm{CH})$, número de inflorescências planta ${ }^{-1}(\mathrm{NI})$ e número de folhas planta $^{-1}(\mathrm{NF})$ das cultivares.

\begin{tabular}{lllll}
\hline Cultivares & NR & $\mathrm{CH}$ & $\mathrm{NI}$ & $\mathrm{NF}$
\end{tabular}

\begin{tabular}{llllr}
\hline BR3-Tracuateua & $3,60 \mathrm{ab}$ & 72,90 & 7,23 & 10,23 \\
BRS & $2,12 \mathrm{bc}$ & 69,90 & 6,00 & 9,35
\end{tabular}

\section{Urubuquara}

\begin{tabular}{lcccc} 
BRS Milênio & $4,10 \mathrm{a}$ & 95,37 & 7,33 & 11,03 \\
Pretinho & $1,30 \mathrm{c}$ & 87,95 & 6,03 & 9,70 \\
\hline Média & 2,78 & 81,53 & 6,64 & 10,08 \\
DMS & 1,51 & 33,93 & 3,96 & 2,37 \\
CV \% & 24,64 & 18,83 & 27,00 & 10,64
\end{tabular}

Médias seguidas de mesma letra, não diferem em nível de 5\% pelo teste Tukey; DMS = diferença mínima significativa; $\mathrm{CV}=$ coeficiente de variação.

Foi encontrada para variedade BR3-Tracuateua correlação positiva altamente significativa entre o $\mathrm{CH}$ e o NF e entre NR e NF a $1 \%$ de probabilidade, e a $5 \%$ para o $\mathrm{CH}$ e NR (Tabela 3 ). Ocorreu correlação negativa a $1 \%$ de probabilidade entre o CH e NI, NI e NF, ou seja, observou-se associação inversa com variáveis entre as características biométricas, uma vez que a correlação foi negativa e este resultado não é interessante do ponto de vista de produção da cultura.

Quanto ao NR e NF, ocorreu forte correlação positiva e significativa, já para o NI e NR não houve correlação significativa. Enquanto que para a cultivar BRS Urubuquara não foi encontrada correlação significativa pelo coeficiente de Pearson quanto as características biométricas (Tabela 3).

Para a cultivar BRS Milênio observou-se uma correlação positiva significativa entre o NR e NF a $1 \%$ de probabilidade, correlação negativa a $5 \%$ para o NI e NF e entre NR e NI. Esta sendo relação inversa não é de interesse para o desempenho da cultivar, sendo o mais indicado observar uma relação direta. Não foi encontrada correlação significativa pelo coeficiente de Pearson para as características biométricas da cultivar Pretinho (Tabela 3). 
Tabela 3 - Correlação das cultivares: BR3-Tracuateua, BRS Urubuquara, BRS Milênio e Pretinho.

\begin{tabular}{|c|c|c|c|c|c|}
\hline \multirow[t]{2}{*}{ Cultivares } & \multicolumn{5}{|c|}{ BR3 - Tracuateua } \\
\hline & & $\mathrm{CH}$ & NF & NI & NR \\
\hline & $\mathrm{CH}$ & - & $0,827 * *$ & $-0,825 * *$ & $0,560^{*}$ \\
\hline \multirow[t]{6}{*}{ BR3-Tracuateua } & NF & - & - & $-0,905$ & $0,836 * *$ \\
\hline & NI & - & - & - & $-0,524$ \\
\hline & NR & - & - & - & - \\
\hline & & \multicolumn{4}{|c|}{ BRS Urubuquara } \\
\hline & & $\mathrm{CH}$ & $\mathrm{NF}$ & NI & NR \\
\hline & $\mathrm{CH}$ & - & $-0,049$ & $-0,652$ & $-0,160$ \\
\hline \multirow{7}{*}{$\begin{array}{l}\text { BRS } \\
\text { Urubuquara }\end{array}$} & NF & - & - & $-0,677$ & $-0,045$ \\
\hline & & & & & \\
\hline & NI & - & - & - & 0,407 \\
\hline & NR & - & - & - & - \\
\hline & & \multicolumn{4}{|c|}{ BRS Milênio } \\
\hline & & $\mathrm{CH}$ & $\mathrm{NF}$ & NI & NR \\
\hline & $\mathrm{CH}$ & - & $-0,366$ & $-0,281$ & 0,097 \\
\hline \multirow[t]{6}{*}{ BRS Milênio } & NF & - & - & $-0,573^{*}$ & $0,873 * *$ \\
\hline & $\mathrm{NI}$ & - & - & - & $-0,615^{*}$ \\
\hline & NR & - & - & - & - \\
\hline & & \multicolumn{4}{|c|}{ Pretinho } \\
\hline & & $\mathrm{CH}$ & $\mathrm{NF}$ & NI & NR \\
\hline & $\mathrm{CH}$ & - & 0,637 & 0,220 & 0,322 \\
\hline \multirow[t]{3}{*}{ Pretinho } & NF & - & - & 0,695 & $0,934 * *$ \\
\hline & $\mathrm{NI}$ & - & - & - & 0,717 \\
\hline & NR & - & - & - & - \\
\hline
\end{tabular}

**Significativo a $1 \%$ de probabilidade; *Significativo a $5 \%$ de probabilidade.

\section{CONCLUSÕES}

A cultivar Pretinho apresentou-se menos produtivo para o número de ramos em relação aos cultivares: BR3-Tracuateua e BRS Milênio. No entanto, apesar das cultivares apresentarem desempenho semelhante, são recomendados novos experimentos com maior número de acessos e repetições.

As correlações entre as características biométricas em cultivares de feijão-caupi indicam, que quanto maior o número de folhas, maior será o número de ramos e menor será o número de 
inflorescência, exceto as cultivares: BRS Urubuquara e Pretinho, logo as cultivares BRS-Tracuateua e Milênio apresentam as correlações mais explicativas em relação ao potencial de produção baseados nas características biométricas dessas cultivares de feijão-caupi.

\section{REFERÊNCIAS}

ALBUQUERQUE, J.A.A.; SEDIYAMA, T.; SILVA, A.A.; ALVES, J.M.A.; UCHÔA, S.C.P. Cultivo de mandioca e feijão em sistemas consorciados realizado em Coimbra, Minas Gerais. Revista Ciência Agronômica, Ceará, v. 43, p. 532-538, 2012.

ALVES, S.V.; ALVES, S.S.V.; CAVALCANTI, M.L.F.; DEMARTELAERE, A.C.F.; LOPES, W.A.R. Produção de feijão-caupi em função de diferentes dosagens e concentração de biofertilizantes. Revista Verde de Agroecologia e Desenvolvimento Sustentável, Mossoró, v.4, p.45-49, 2009.

ANDRADE JÚNIOR, A.S. Viabilidade da irrigação, sob risco climático e econômico, nas microrregiões de Teresina e Litoral Piauiense. 2000. 566f. Tese (Doutorado) - Escola Superior de Agricultura Luiz de Queiroz, Piracicaba, 2000.

BASTOS, T.X.; ROCHA, E.J.P. da; ROLIM, P.A.M.; DINIZ, T.D. de A.S.; SANTOS, E.C.R. dos; NOBRE, R.A.A.; CUTRIM, E.M.C.; MENDONÇA, R.L.D. de. O estado atual dos conhecimentos de clima da Amazônia brasileira com finalidade agrícola. In: SIMPÓSIO DO TRÓPICO ÚMIDO, 1., 1984, Belém, PA. Anais... Belém, PA: Embrapa- CPATU, 1986, v.1, p.19-36. (EmbrapaCPATU. Documentos, 36).

CRAVO, M.S.; VIÉGAS. I.J.M.; BRASIL, E.C. (Ed.). Recomendações de adubação e calagem para o Estado do Pará. Belém: Embrapa Amazônia Oriental, 2007. 262 p.

FREIRE FILHO, F.R.; RIBEIRO, V.Q.; SANTOS, A.A. Cultivares de caupi para a região MeioNorte do Brasil. In: Cardoso, M.J. (Org.). A cultura do feijão-caupi no Meio-Norte do Brasil. Teresina: Embrapa Meio-Norte, 2000, 246p. (Embrapa Meio-Norte. Circular Técnica, 28).

FREIRE FILHO, F.R.; RIBEIRO, V.Q.; ROCHA, M.M.; LOPES, A.C.A. Adaptabilidade e estabilidade de rendimento de grãos de genótipos de caupi de porte semi-ereto. Revista Científica Rural, Santa Maria, v.6, p.31-39, 2001.

FREIRE FILHO, F.R.; RIBEIRO, V.Q.; ROCHA, M.M.; LOPES, A.C.A. Adaptabilidade e estabilidade da produtividade de grãos de linhagens de caupi de porte ereto enramador. Revista Ceres, Viçosa, v.49, p.383-393, 2002.

FREIRE FILHO, F.R.; CRAVO, M. da S.; RIBEIRO, V.Q.; ROCHA, M. de M.; CASTELO, E. de O.; BRANDÃO, E. dos S.; BELMINO, C.S.; MELO, M.Í.S. de. BRS Milênio e BRS Urubuquara: cultivares de feijão-caupi para a região Bragantina do Pará. Revista Ceres, Viçosa, v.56, p.749-752, 2009.

OLIVEIRA, J.P.F.; GONÇALVES, M.V.; MARTINS, J.D.L.; ZUMBA, J. da SILVA.; LIVEIRA, M.; SANTOS, I.B.; MOURA, M.F. Componentes de produção de feijão-caupi (Vigna unguiculata 
(L.) Walp.) adubado com composto orgânico, biofertilizante e inoculantes. In: CONGRESSO NACIONAL DE FEIJÃO - CAUPI, 3., 2013, Recife. Resumos... Recife: CONAC, 2013.

PIMENTEL-GOMES, F. Curso de estatística experimental. 13. Ed. São Paulo: Nobel, 2000. 479 p.

SANTOS, J.F. dos.; GRANGEIRO, J.I.T.; BRITO, C.H. de.; SANTOS, M. do C. C. A. Produção e componentes produtivos de variedades de feijão-caupi na microrregião cariri paraibano.

Engenharia Ambiental, v.6, p.214-222, 2009.

SILVA, R.P. Inoculação com rizóbio em caupi no sertão da Paraíba. Dissertação de Mestrado, Universidade Federal Rural de Pernambuco, Recife, Pernambuco. 2006, 41p. 